\title{
Customer Value Analysis of Small and Medium Enterprises in Internet Environment
}

\author{
Biao Tong ${ }^{1,}$,, Liang $\mathrm{Li}^{2, \mathrm{~b}}$ \\ ${ }^{1}$ College of economics and management, Zhejiang University of Technology, Zhejiang 310023, \\ China; \\ ${ }^{2}$ College of economics and management, Zhejiang University of Technology, Zhejiang 310023, \\ China;. \\ a18989471890@163.com, bsuifengluanpiao@163.com,
}

Keywords: Small and Medium Enterprises (SMEs), Internet, Customer Value

\begin{abstract}
With the rapid development and popularity of Internet and the approach of customer economy era, the business environment of enterprises has undergone tremendous changes, and the traditional business model is increasingly challenged, particularly in the current significant trend-homogenization of products and services. On the basis of the analysis of customer value, this paper sums up two methods of customer value classification: the traditional purchase-based customer value, the customer perception-based customer value. Meanwhile, combining with the actual SMEs, and based on the customer perceived value, this paper proposes the customer value model of SMEs, which consists of four dimensions: product perception, price perception, service perception and the relationship perception.
\end{abstract}

\section{Introduction}

With the rapid development and popularity of Internet and the approach of customer economy era, enterprises all over the world are experiencing a profound transformation. The business environment of enterprises has undergone tremendous changes, and the traditional business model is increasingly challenged, particularly in the current significant trend-homogenization of products and services. Customer resource has become the most important resource of an enterprise. Past attempts have largely looked internally within the organization for improvement, such as reflected by quality management, reengineering, downsizing, and restructuring. And the next important source for competitive advantage will come from more outward orientation toward customers, as indicated by the many calls for organizations to compete on superior customer value delivery [1].

The most direct reason of the formation of the relationship between the customer and enterprise is the value that needs to transfer between them, the relationship between the customer and enterprise will not be exist without the value. The concept of customer value is becoming increasingly used in strategy and marketing literature in recent years. Customer value is considered central to competitive advantage and long-term success of business organizations [2]. At all stages of customer relationship management, from customer acquisition, customer identification, customer segmentation, customer retention and loss management, to customer satisfaction and customer loyalty analysis and customer value management and customer life cycle value management, the evaluation of customer value is always the core issue. Customer resource is the most important resource of an enterprise, customers have value, but not all customers can bring benefits for the enterprise. Wyner (1996) pointed out that in an enterprise, $80 \%$ of the sales profit is from $20 \%$ of customers, while the rest $20 \%$ of the sales profit spent $80 \%$ of the company's marketing costs [3].From this, we can know that find out the customers who have value is very important for the benefit of the enterprise. So what kind of customer can bring more benefits for the enterprise? What is the standard of such a customer? To answer these questions, we need to make analysis on customer value. Customer value analysis is an analysis and evaluation of customer satisfaction degree and satisfaction degree.

This paper researches on the customer value analysis of small and medium enterprises (SMEs) 
in internet environment. On the basis of the analysis of customer value, this paper sums up two methods of customer value classification: the traditional purchase-based customer value, the customer perception-based customer value, and the customer lifetime-based customer value. Meanwhile, combining with the actual SMEs, and based on the customer perceived value, this paper proposes the customer value model of SMEs, which consists of four dimensions: product perception, price perception, service perception and the relationship perception.

\section{Customer Value Analysis of SMEs in Internet Environment}

Small and medium-sized enterprise is a special enterprise group, has its unique characteristics of enterprise, and the customers of small and medium-sized enterprise also have their own characteristics relative to large enterprise customers. The goal of customer relationship management in small and medium sized enterprises is to identify high value customers, put the limited resources of the enterprise into the acquisition and retention of high value customers.

\subsection{Analysis from the perspective of monetary value}

Customer purchasing behavior is the source of corporate profits, is the most significant and most direct embodiment of customer value, and also is the most convenient and accurate method for quantitative evaluation of customer value. Through simple calculation of customer transaction data, we can get convenient access to customer transactions, the customer's profit contribution and other key information to determine who is a high value customer [4].

In fact, it is more important to judge the value of potential customers, especially for SMEs. Due to limited financial resources and lacking of brand attraction, acquiring new customers is more difficult for SMEs. Facing massive customer market, if you cannot effectively identify high value customers and get a certain number of new customers, your enterprise will not survive. So enterprises should pay attention to the customer non-monetary value. Customer non-monetary value refers to the customer value in addition to customer and enterprise transaction data, such as word-of-mouth customers value, customer interactions value. Word-of-mouth customers value, especially Internet word-of-mouth value in Internet environment, can make great influence on promotion of corporate reputation and new customer acquisition. Customer interactions value such as customers' suggestions for enterprises, can make great influence on decision making and further development of enterprises.

\subsection{Analysis from the perspective of customer perceived value}

From the perspective of customer perceived value, customer perceived value is customer's overall evaluation after customer's perceived benefits is weighed against the cost of obtaining a product or service [4]. Therefore, customer value has a strong subjectivity. From this point of view, high value customers is a customer with high customer value perception. From the previous theory, customer perceived value is composed of customer perceived gains and perceived cost. Perceived gains include factors such as products, services, personnel, image and so on, and perceived costs include currency, time, physical effort, mind and other factors. Under different economic conditions, customer perceived gains and perceived costs are varied. Even in the same condition, customer perceived value is likely to be different when same quality products sold to different customers at the same price, because different customers have different customer characteristics and different values feelings. Therefore, from the perspective of customer perception of customer value, it is difficult to do quantitative calculation. So qualitative analysis method is often taken to do the classification of customer value. Customer perceived value is the basis of customer satisfaction, the customer perceived value must be improved if enterprises want to improve customer satisfaction, and the best way to improve customer perceived value is to increase customer perceived gains while reducing customer perceived cost. 


\section{Customer value model for SMEs based on the perspective of customer perceived value}

According to the above analysis, every kind of customer value research perspective has its rationality and advantages, but there are also short comings. A good model of application is to integrated with the above methods when evaluating customer value, however, it is quite difficult to integrate two methods in practical application, and it will also cause the customer value evaluation to be more complex. Based on the study of these two perspectives and combined with the actual situation of SMEs in Internet environment, this paper proposes a customer value model for SMEs with four dimensions, as is shown in Figure 1.

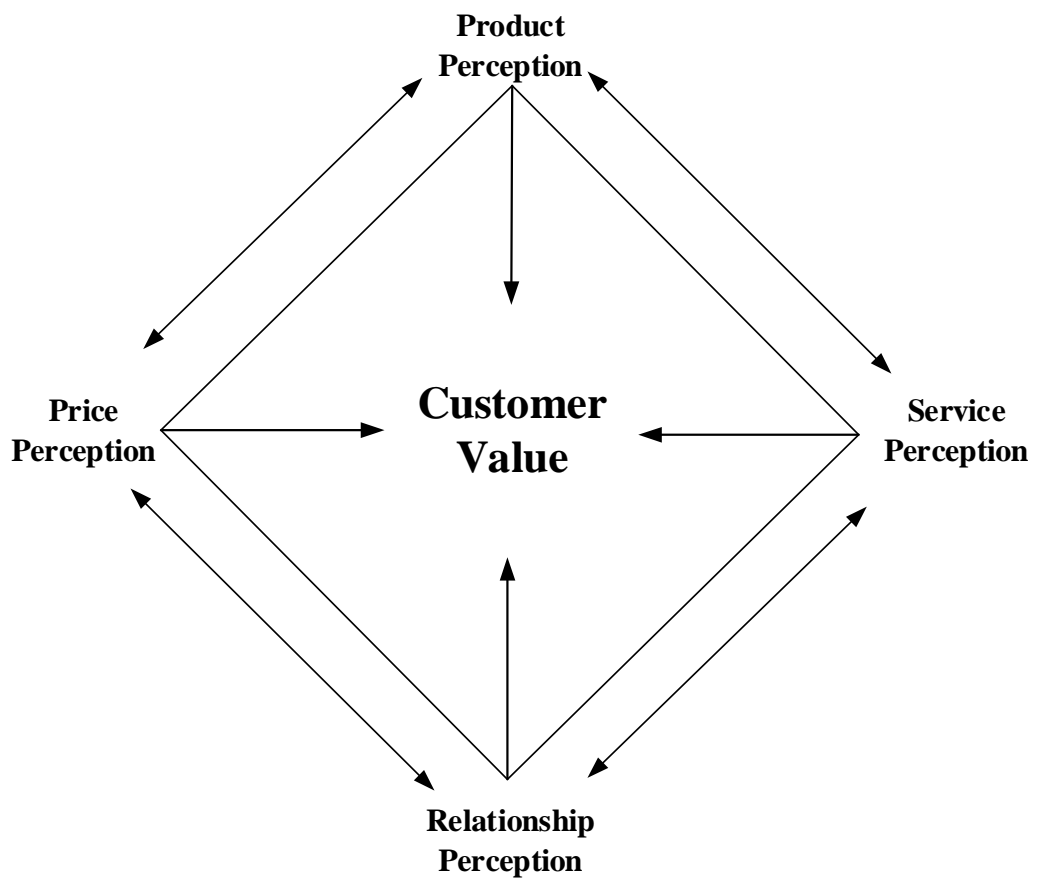

Figure 1 customer value model for SMEs

The customer value model for SMEs consists of four dimensions, product perception, price perception, service perception and relationship perception, these four dimensions interact with each other and take combined effects on the customer value. Product perception is an objective evaluation of the enterprise products offered by customers, such as whether the quality of the product meets customers' expectations, whether the functions of product meet customers' needs, whether the design of the product meets the customer's preferences and so on. Product value is the basis of customer value of SMEs and it is the basic factor that affects the customer value evaluation of SMEs. Price perception is an objective evaluation of the product's price offered by customers, such as whether product pricing is reasonable, how is the performance cost ratio and so on. Service perception is an objective evaluation of the service offered by customers before the purchase, during the purchase and after the purchase, including service personnel quality, service response time, service quality and so on. Relationship perception is the strength of the relationship between the customer and the enterprise, it is the objective and subjective evaluation of the relationship between enterprises and customers. Based on the activities that establish and maintain relations between enterprises and customers, relationship perception include the time length of relationship, the intensity of relationship and transfer cost of relationship.

\section{Conclusion}

On the basis of the analysis of customer value, this paper sums up two methods of customer value classification: the traditional purchase-based customer value, the customer perception-based customer value, and the customer lifetime-based customer value. Meanwhile, combining with the actual SMEs, and based on the customer perceived value, this paper proposes the customer value 
model of SMEs, which consists of four dimensions: product perception, price perception, service perception and the relationship perception. Besides ensuring the quality of products, SMEs should use the advantage of the flexibility of management and the rapid adaptation to market, to seek a breakthrough on product function value-added and personality needs of product design.

\section{References}

[1] Woodruff R B. Customer value: the next source for competitive advantage[J]. Journal of the academy of marketing science, 1997, 25(2): 139-153.

[2] Salem Khalifa A. Customer value: a review of recent literature and an integrative configuration[J]. Management decision, 2004, 42(5): 645-666.

[3] Wyner G A. Customer Profitability: Linking Behavior to Economics [J]. Journal of Marketing Research, 1996, 8(2):36-38.

[4] Menon A, Homburg C, Beutin N. Understanding customer value in business-to-business relationships[J]. Journal of Business-to-Business marketing, 2005, 12(2): 1-38.

[5] Yang Z, Peterson R T. Customer perceived value, satisfaction, and loyalty: The role of switching costs[J]. Psychology \& Marketing, 2004, 21(10): 799-822. 